\title{
Optimization Drilling Parameters of Aluminum Alloy Based on Taguchi Method
}

\author{
Aseel Jameel Haleel \\ Department of Production Engineering and Metallurgy/University of Technology \\ Email: en.aseel@yahoo.com
}

(Received 5 June 2017; accepted 4 December 2017)

https://doi.org/10.22153/kej.2018.12.001

\begin{abstract}
This paper focuses on the optimization of drilling parameters by utilizing "Taguchi method" to obtain the minimum surface roughness. Nine drilling experiments were performed on Al 5050 alloy using high speed steel twist drills. Three drilling parameters (feed rates, cutting speeds, and cutting tools) were used as control factors, and L9 (33) "orthogonal array" was specified for the experimental trials. Signal to Noise (S/N) Ratio and "Analysis of Variance" (ANOVA) were utilized to set the optimum control factors which minimized the surface roughness. The results were tested with the aid of statistical software package MINITAB-17. After the experimental trails, the tool diameter was found as the most important factor that has effect on the surface roughness. The optimal drilling factors that minimized the surface roughness are $(20 \mathrm{~mm} / \mathrm{min}$ cutting speed, $0.2 \mathrm{~mm} / \mathrm{rev}$ feed rate, and $10 \mathrm{~mm}$ tool diameter).
\end{abstract}

Keywords: Analysis of Variance (ANOVA), Drilling operation, Surface roughness, Taguchi method.

\section{Introduction}

The significant aim in the modernistic industry is to produce the products with great quality and smallest cost in smallest time. Drilling process is essential for manufacturing industries and excessively used in the automotive industries, aircraft, and aerospace. Although the new metal cutting methods have improved in the manufacturing environment, traditionally drilling operation till now considered one of the most popular machining operations [1]. Aluminum is utilized in many industries to produce various products and is important to the world economy. Aluminum and aluminum alloys are very significant in different industries in which the durability, strength, and light weight are required. Hole quality characteristics is very significant in different application, which involve the hole diameter accuracy and the hole surface finishing. Hole quality mostly dependent on the drilling tools and the cutting parameters which is can be optimized by using different methods such as "Taguchi" approach and regression models. Taguchi approach considers a good tool to design a system with top quality and excessively used in engineering analysis [3], for this reason many researchers concentrated on determining the best surface roughness and roundness error. Taso and Hochen (2008) implemented the estimation and assessment of trust force and surface roughness in the composite material drilling operation utilizing "Taguchi" method and "neural network". The tested results proved that the spindle speed and feed rate the most affecting to the surface roughness, while the drill diameter and feed rate are the most affecting to the thrust force [4]. Kurt et al.(2009) used the "Taguchi" approach to optimize the cutting parameters of the hole diameter accuracy and surface finish in dry drilling operations [2].

Kilickap (2010) inspected the effect of cutting parameters, such as surface roughness, point angle on burr height, cutting speed, and feed rate 
produced when drilling AL 7075. Taguchi "orthogonal array"L27, "Signal-To-Noise" ratio and "ANOVA" was used to find the best drilling parameters of AL7075 [5].

Tosun (2011) considered different factors in drilling Aluminum-silicon carbide particulate $\left(\mathrm{Al} / \mathrm{SiC}_{\mathrm{p}}\right)$ metal matrix composite such as drill type, feed rate, spindle speed, heat treatment and point angle of drill. Two factors (feed rate and tool type) determined as the important factors that effect on hole surface roughness [6]

Çiçek et al. (2012) investigated the optimal control factors for the hole quality of drilling AISI 316austenitic stainless steel with M35 High Speed Steel (HSS) twist drills by utilizing Taguchi technique [3].

Navanth and Karthikeya Sharma (2013) utilized "Taguchi" approach to get the minimal surface roughness (Ra). Taguchi "orthogonal array" L18 used to perform the drilling tests. The feed rate, cutting tool, and spindle speed were considered as control factors [1].

Kabakli et al. (2014) show an assessment of the geometric accuracies and roughness in drilling process using U-drills. Surface roughness, perpendicularity and cylindricity used as a parameters for assessment the affecting of the feed rate, speed, hole diameter and depth. The execution characteristics were measured and Taguchi method, "Signal-To-Noise" ratio and "ANOVA" were used to analysis the effects of the controlled factors at various levels to identify the optimal drilling circumstance for U-drills [7].

\subsection{Drilling Process}

Drilling is one of the machining process which are used for differ purposes. The basic purpose of drilling process is to drilling cylindrical holes in workpieces. The holes are cut out material with cutting tool, which is known as drill. The end cutting tool used for drilling the workpeice called twist drill which is provided with two cutting edges. The drill is fixed in rotating spindle and cab be feed towards the workpiece. The spindle speed and the feed rate can be changed according to the workpeice. Figure (1) shows the two motion of twist drill [8].

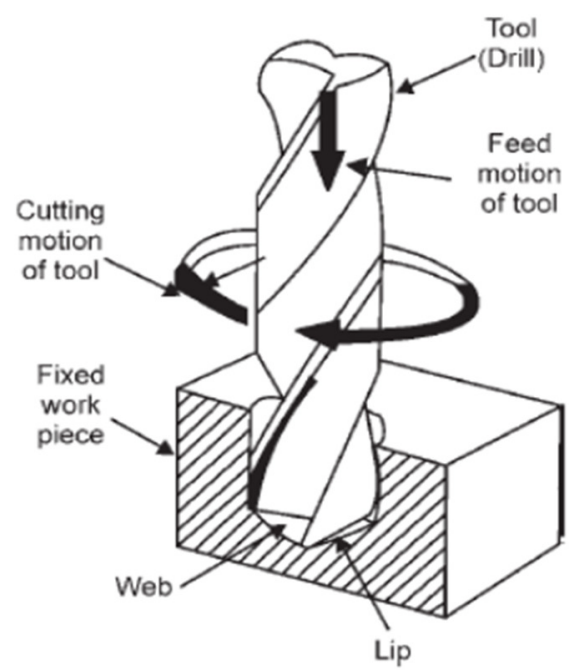

Fig. 1. Twist Drill Motion [8]

\subsection{The Surface Roughness}

Surface roughness is considering one of the main characteristics in metal cutting. Surface roughness result from drilling process impact on the mechanical properties such as creep life, corrosion resistance, fatigue behavior and so on. Surface roughness expressed by the vertical variations of the actual surface from its typical form. If these variations are great, the surface is rough. If they are few the surfaces is smooth. Surface roughness usually measured by a device in which the stylus moves across the surface, the stylus movement is magnified and the signal record. The result is mostly express as (Ra) or average roughness [9].

\section{Methodology}

\section{Taguchi Approach}

Traditional experimental design methods are difficult and sophisticated to use. when the process parameters increases, the numbers of implemented tests should be increased, so Taguchi method used to solve this problem. In Taguchi method a specific design of "orthogonal arrays" used to study the total parameter with only few numbers of experiments. Then, the results converted in to "Signal-ToNoise $(\mathrm{S} / \mathrm{N})$ Ratio to measure the quality characteristics corrupted from the required values. In order to assess the optimal parameter, generally there are three categories of "Signal-To-Noise"(S / N) Ratios [3]: 
"Smaller- The -Better"

The "Signal -To -Noise" Ratio for "Smaller -TheBetter" is shown in equation (1).

$\frac{\mathrm{s}}{\mathrm{N}}=-10 \log \left[\frac{1}{\mathrm{n}} \sum_{\mathrm{i}=1}^{\mathrm{n}} \mathrm{y}_{\mathrm{i}}^{2}\right]$

$>$ "Higher- The- Better"

The "Signal -To -Noise" Ratio for the "Higher-

The- Better" is shown in equation (2).

$\frac{S}{N}=-10 \log \frac{1}{n} \sum_{i=1}^{n} \frac{1}{\mathrm{y} 2}$

\section{"Nominal- The- Better"}

The "Signal- To- Noise" Ratio for the "Nominal-

The- Better" is shown in equation (3).

$\frac{S}{N}=10 \log \frac{Y}{S_{y}^{2}}$

Where:

y average of observed data

y observed

n observations number

$S^{2} y \quad$ variances of $y$.

In this study, the drilling parameters were

determined by using taguchi experimental design method. Taguchi "orthogonal arrays", S/N ratio, and ANOVA, used to analyze the impact of the drilling parameters on surface roughness [10].

\section{Experimental Details \\ 3.1 Workpiece Materials}

One of the commercial aluminum alloys was chosen as the work piece material for the test sample. The dimension of work piece was (330mm x $80 \mathrm{~mm} \times 20 \mathrm{~mm})$. Table (1) shows the chemical composition of the alloy. The diameters of the drill were $(6 \mathrm{~mm}, 8 \mathrm{~mm}$, and $10 \mathrm{~mm}$ ) and the used cutting tool was high speed steel (HSS) twist drill.

Table 1,

Chemical Composition of (Al) Alloy Grade 5050.

\begin{tabular}{ll}
\hline Elements & Composition \% \\
\hline $\mathrm{AL}$ & 96.7 \\
$\mathrm{Mg}$ & 1.8 \\
$\mathrm{Fe}$ & 0.8 \\
$\mathrm{Si}$ & 0.4 \\
$\mathrm{Mn}$ & 0.1 \\
$\mathrm{Cu}$ & 0.2 \\
\hline
\end{tabular}

\subsection{Selection of Control Factors and Orthogonal Array}

Three factors were chosen for this experiment. There are cutting speed, feed rate and drill diameter with three levels as shown in table (2).
Table 2,

Experimental factors and levels

\begin{tabular}{llll}
\hline Factors & Level 1 & Level 2 & Level 3 \\
\hline $\begin{array}{l}\text { A: Cutting speed } \\
\text { (m/min) }\end{array}$ & 15 & 20 & 25 \\
$\begin{array}{l}\text { B: Feed rate } \\
\text { (mm/rev) }\end{array}$ & 0.1 & 0.2 & 0.3 \\
$\begin{array}{l}\text { C: Tool diameter } \\
(\mathrm{mm})\end{array}$ & 6 & 8 & 10 \\
\hline
\end{tabular}

In Taguchi approach the first step is to choose the "orthogonal array", the "orthogonal array"L9 $\left(3^{3}\right)$ was chosen to get the best drilling parameters. Table (3) shows Taguchi L9 "orthogonal array" and table (4) shows the Control factors using "orthogonal array".

Table 3,

Taguchi L9 "Orthogonal Array"

\begin{tabular}{|c|c|c|c|}
\hline $\begin{array}{l}\text { Experiments } \\
\text { Number }\end{array}$ & A & B & C \\
\hline 1 & 1 & 1 & 1 \\
\hline 2 & 1 & 2 & 2 \\
\hline 3 & 1 & 3 & 3 \\
\hline 4 & 2 & 1 & 2 \\
\hline 5 & 2 & 2 & 3 \\
\hline 6 & 2 & 3 & 1 \\
\hline 7 & 3 & 1 & 3 \\
\hline 8 & 3 & 2 & 1 \\
\hline 9 & 3 & 3 & 2 \\
\hline
\end{tabular}

Table 4,

Control Factors Using "Orthogonal Array"

\begin{tabular}{llll}
\hline $\begin{array}{l}\text { Experimens } \\
\text { Number }\end{array}$ & \multicolumn{3}{c}{ Levels } \\
\cline { 2 - 4 } & $\begin{array}{l}\text { Cutting } \\
\text { speed(mm/min) }\end{array}$ & $\begin{array}{l}\text { Feed } \\
\text { rate(mm/rev) }\end{array}$ & $\begin{array}{l}\text { Tool } \\
\text { diameter } \\
\text { (mm) }\end{array}$ \\
\hline 1 & 15 & 0.1 & 6 \\
2 & 15 & 0.2 & 8 \\
3 & 15 & 0.3 & 10 \\
4 & 20 & 0.1 & 8 \\
5 & 20 & 0.2 & 10 \\
6 & 20 & 0.3 & 6 \\
7 & 25 & 0.1 & 10 \\
8 & 25 & 0.2 & 6 \\
9 & 25 & 0.3 & 8 \\
\hline
\end{tabular}

\subsection{Sample Preparation}

In this paper, the drilling process was executed by using (CNC FANUC Series Oi-MB) which is shown in fig.2, besides that, (Mahr / MarSurf PS1) were used to measure the surface roughness which is shown in fig. 3. The measurement of roughness repeated (3 time) at various positions on the drilled surface. 
The average roughness parameters were selected as the output parameter to define the geometric irregularities of the surface drilled in different conditions. Fig4 shows the twist HSS drill with diameters $(6,8$, and10) $\mathrm{mm}$. Fig. 5 shows the sample of the work piece with (9 through holes),

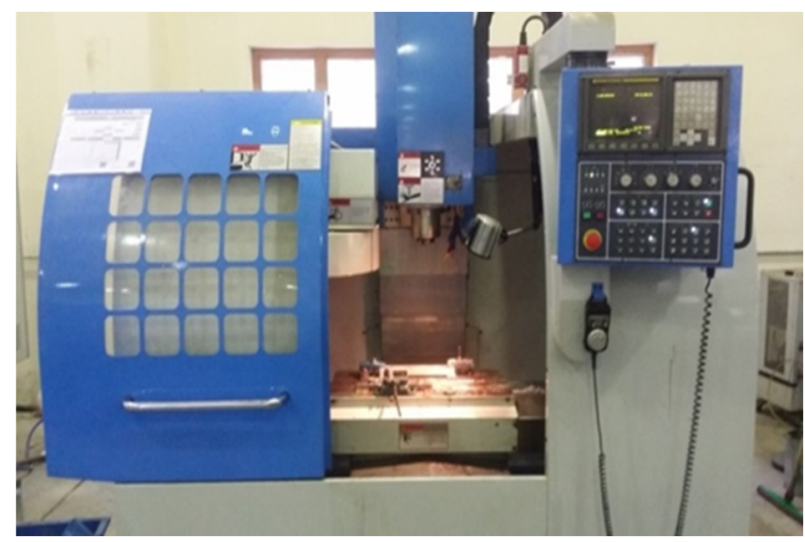

Fig. 2. CNC FANUC Series Oi-MB.

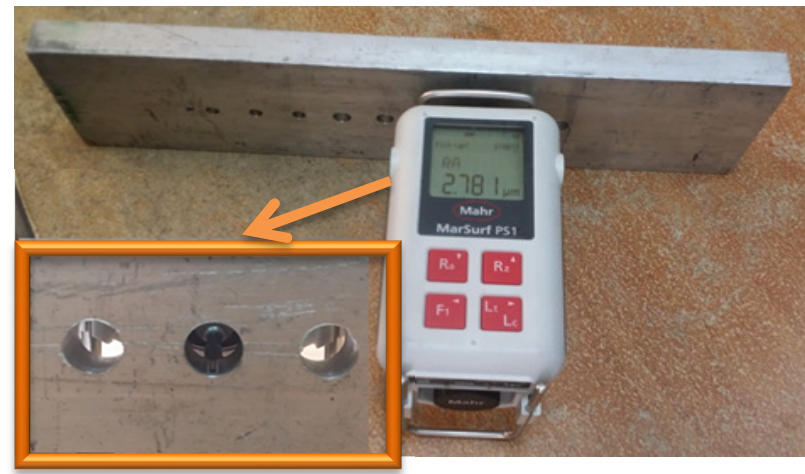

Fig. 3. Surface Roughness Device (Mahr / MarSurf PS1).

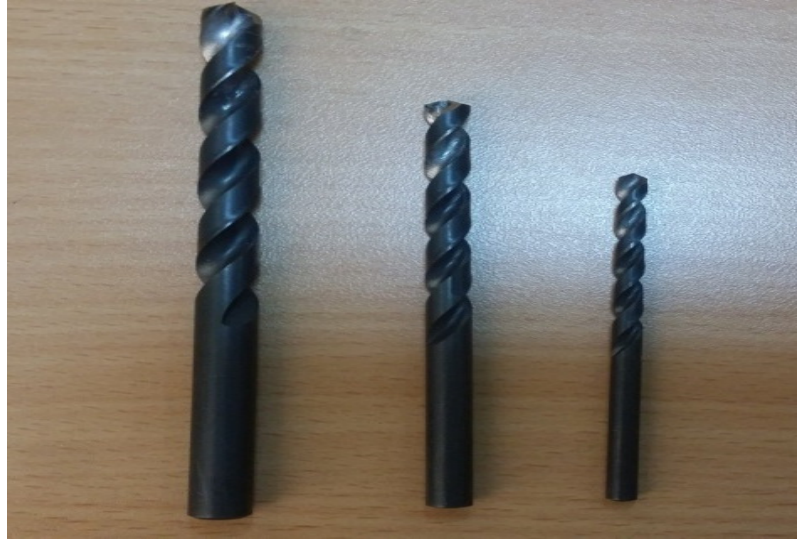

Fig. 4. Twist HSS Drill with Diameters $(6,8$, and 10) mm.

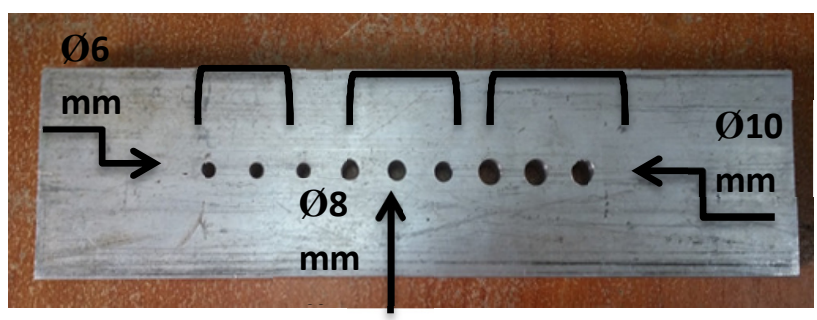

Fig. 5. The Sample of the Workpiece

\subsection{Analysis of "Signal -To -Noise" Ratio}

Taguchi approach used Signal To Noise $(\mathrm{S} / \mathrm{N})$ ratio to calculate the variance of the experimental design. The equation of (Smaller-the-Better) was chosen to calculate the $(\mathrm{S} / \mathrm{N})$ ratio, because the smallest value of surface roughness is required to get a good product quality. Table (5) shows the result of surface roughness $\left(\mathrm{R}_{\mathrm{a}}\right)$ and $(\mathrm{S} / \mathrm{N})$ ratio of the surface roughness.

Table 5.

The Result of Surface Roughness $\left(R_{a}\right)$ and $(S / N)$ Ratio.

\begin{tabular}{lllllllll}
\hline $\begin{array}{l}\text { Experiments } \\
\text { Number }\end{array}$ & $\begin{array}{l}\text { Levels } \\
\text { Cutting } \\
\text { speed } \\
(\mathbf{m m} / \mathbf{m i n})\end{array}$ & $\begin{array}{l}\text { Feed rate } \\
(\mathbf{m m} / \mathbf{r e v})\end{array}$ & $\begin{array}{l}\text { Tool } \\
\mathbf{d i a m e t e r} \\
(\mathbf{m m})\end{array}$ & $\begin{array}{l}\text { Surface Roughness } \\
(\mathbf{R a} \boldsymbol{\mu m}) \\
\text { Trail 1 }\end{array}$ & Trail 2 & Trail 3 & $\begin{array}{l}\text { Average } \\
(\text { Ra) }\end{array}$ & $\begin{array}{l}\text { S/N } \\
\text { Ratio }\end{array}$ \\
\hline $\mathbf{1}$ & 15 & 0.1 & 6 & 0.275 & 0.375 & 0.439 & 0.363 & 8.801867 \\
$\mathbf{2}$ & 15 & 0.2 & 8 & 1.754 & 2.050 & 1.763 & 1.855667 & -5.37 \\
$\mathbf{3}$ & 15 & 0.3 & 10 & 1.969 & 2.795 & 2.222 & 2.328667 & -7.34215 \\
$\mathbf{4}$ & 20 & 0.1 & 8 & 1.159 & 1.713 & 1.159 & 1.343667 & -2.56583 \\
$\mathbf{5}$ & 20 & 0.2 & 10 & 3.204 & 2.684 & 1.735 & 2.541 & -8.10009 \\
$\mathbf{6}$ & 20 & 0.3 & 6 & 0.938 & 0.754 & 0.597 & 0.763 & 2.349509 \\
$\mathbf{7}$ & 25 & 0.1 & 10 & 2.755 & 2.686 & 3.450 & 2.963667 & -9.43659 \\
$\mathbf{8}$ & 25 & 0.2 & 6 & 0.547 & 0.720 & 0.807 & 0.691333 & 3.20625 \\
$\mathbf{9}$ & 25 & 0.3 & 8 & 1.027 & 1.306 & 1.298 & 1.210333 & -1.6581 \\
\hline
\end{tabular}




\section{5 "Analysis of Variance" (ANOVA)}

The "Analysis of Variance" (ANOVA) is a powerful and common method of dividing total variation in to accountable sources of variation in an experiment. It is a statistical method used to explain the experimented data and make decisions about the parameters under study. In this research ANOVA was utilized to analyze the effect of the cutting speed, feed rate, and the drill diameter on the surface roughness of the drilled holes. Table (6) shows the formulas used to conduct the ANOVA analysis.

Table 6,

formulas used to conduct the ANOVA analysis.

\begin{tabular}{|c|c|c|c|}
\hline DF & Degrees of Freedom & $\begin{array}{l}\text { DF Factor }=r-1 \\
\text { DF Error }=n_{T}-1\end{array}$ & $\begin{array}{l}\mathrm{r}: \text { number of factor levels } \\
\mathrm{n}_{\mathrm{T}} \text { : total number of Observations }\end{array}$ \\
\hline SS & Sum of Squares & $\begin{array}{l}\text { SS Factor }=\sum n_{i}(\overline{y i}-\bar{y})^{2} \\
\text { SS Error }=\sum_{\mathrm{i}} \sum_{j}(\overline{\text { yij }}-\overline{y i})^{2}\end{array}$ & $\begin{array}{l}\mathrm{y}_{\mathrm{i}}: \text { mean of observations at } \mathrm{i}^{\text {th }} \text { factor } \\
\text { level } \\
\mathrm{y}: \text { mean of all observation } \\
\mathrm{y}_{\mathrm{ij}}: \text { value of } \mathrm{j}^{\text {th }} \text { observation at } \mathrm{i}^{\text {th }} \\
\text { factor level }\end{array}$ \\
\hline MS & Mean Squares & $\begin{array}{l}\text { MS Factor }=\frac{\text { SS Factor }}{\text { DF Factor }} \\
M S \text { Error }=\frac{\text { SS Error }}{D F \text { Error }}\end{array}$ & \\
\hline F-Value & F Value & $F=\frac{\text { MSFactor }}{\text { MS Factor }}$ & \\
\hline P-Value & P Coefficient & $\begin{array}{l}\mathrm{P} \text { value indicates that the leve } \\
\text { likely the sample result are, as } \\
\text { range from }(0 \text { to } 1) \text {. A commo }\end{array}$ & $\begin{array}{l}\text { significant effect. Is a measure of how } \\
g \text { the null hypothesis is true. } P \text { value } \\
\text { ed of } P \text { value is } 0.05\end{array}$ \\
\hline
\end{tabular}

\section{Results and Discussion}

Minitab statistical software has been used to analysis of the experimental work. The equation of (the Smaller-The-Better) was chosen to calculate the $(\mathrm{S} / \mathrm{N})$ ratio of surface roughness, the response table for $\mathrm{S} / \mathrm{N}$ ratio of $(\mathrm{Ra})$ shown in table (7) and the effect plots of the drilling parameters for Signal To Noise ratio was drawing using MINITAB17 as shown in figure (6). The plots show the response variations with the changes of drilling parameters, from figure (6) we can notice that in the increase of the drilling conditions (feed rate $\&$ cutting speed) the change in response will be change less than the change in the drilling condition (tool diameter) when we increase it. From the analysis the minimum value of ( $\mathrm{Ra}$ ) achieves at drilling condition of cutting speed of $(20 \mathrm{~m} / \mathrm{min})$, feed rate of $(0.2 \mathrm{~mm} / \mathrm{rev})$ and tool diameter of $(10 \mathrm{~mm})$. Then result of Signal To Noise Ratio analyzed by using ANOVA. In analysis of variance when the $\mathrm{p}$ - value for the drilling factor less than (0.05) then this factor consider significant, and when the $\mathrm{P}$-value greater than (0.05) then the factor consider insignificant. The result of ANOVA of $\mathrm{S} / \mathrm{N}$ ratio for $(\mathrm{Ra})$ shown in table (8). The optimal Drilling condition shown in table (9)

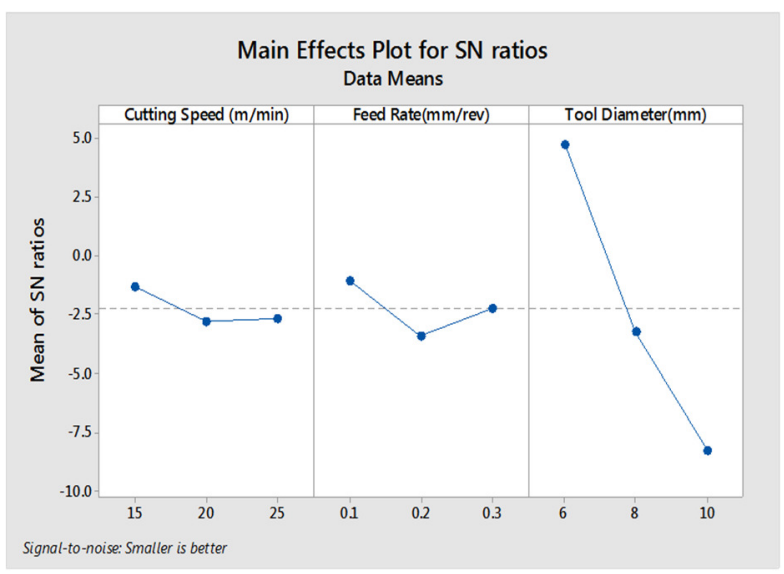

Fig. 6. The Effect Plots for Signal to Noise Ratio. 
Table 7,

Response Table for Signal to Noise Ratios .

\begin{tabular}{llll}
\hline Level & Cutting Speed(m/min) & Feed Rate(mm/rev) & Tool Diameter(mm) \\
\hline 1 & -1.303 & -1.067 & 4.786 \\
2 & -2.772 & -3.421 & -3.198 \\
3 & -2.629 & -2.217 & -8.293 \\
Delta & 1.469 & 2.354 & 13.079 \\
Rank & 3 & 2 & 1 \\
\hline
\end{tabular}

Table 8,

The Result of ANOVA of S/N ratio for (Ra).

\begin{tabular}{lllllc}
\hline Source & DF & Adj SS & Adj MS & F-Value & P-Value \\
\hline Cutting Speed(m/min) & 2 & 3.936 & 1.968 & 0.18 & 0.849 \\
Feed Rate(mm/rev) & 2 & 8.316 & 4.158 & 0.38 & 0.726 \\
Tool Diameter(mm) & 2 & 260.756 & 130.378 & 11.83 & 0.048 \\
Error & 2 & 22.045 & 11.022 & & \\
Total & 8 & 295.053 & & & \\
\hline
\end{tabular}

Where :

DF: Degree of freedom

AdjSS : sequential sum of squares

AdjMS : Mean sum of squares

F-Value : F- Test

P-Value : P-coefficient

Table 9,

Optimal Drilling Condition.

\begin{tabular}{lll}
\hline Factors & Level & Value \\
Cutting & 5 & 20 \\
Speed $(\mathrm{m} / \mathrm{min})$ & & \\
Feed Rate $(\mathrm{mm} / \mathrm{rev})$ & 5 & 0.2 \\
Tool Diameter(mm) & 5 & 10 \\
\hline
\end{tabular}

\section{Conclusions}

In this study, the optimization of drilling parameters were executed by using Taguchi approach to get the optimal surface roughness value in drilling Aluminum alloy grade 5050 with HSS twist drills. Taguchi method, $\mathrm{S} / \mathrm{N}$ ratio, and ANOVA were successfully determining the optimal drilling conditions at level (5). From S/N ratio result based on ranking and ANOVA result based on F- value the tool diameter is the most significant control factor follow by feed rate and the cutting speed has the least significant on surface roughness.

\section{References}

[1]Navanth A., Karthikeya Sharma T." A Study of Taguchi method based optimization of drilling Parameter in Dry Drilling of AL 2014
Alloy Low Speeds" International Journal of Engineering Sciences \& Emerging Technologies, ISSN: 2231 - 6604 Volume 6, Issue 1, pp: 65-75,2013.

[2]Kurt M., Bagci E., Kaynak Y., "Application of Taguchi methods in the optimization of cutting parameters for surface finish and hole diameter accuracy in dry drilling processes", International Journal of Advanced Manufacturing Technology, vol. 40, no. 5-6, p. 458-469, 2009.

[3] Çiçek A. , Kıvak T. , and Samta G. "Application of Taguchi Method for Surface Roughness and Roundness Error in Drilling of AISI 316 Stainless Steel”, Strojniški vestnik Journal of Mechanical Engineering 58: 3, 165174, 2012.

[4]Tsao C.C., Hocheng H., " Evaluation of thrust force and surface roughness in drilling composite material using Taguchi analysis and neural network" , Journal of Materials Processing Technology, vol. 203, no. 1-3, p. 342-348, 2008.

[5]Kilickap E., "Modeling and optimization of burr height in drilling of Al-7075 using Taguchi method and response surface methodology", The International Journal of Advanced Manufacturing Technology, volume 49, Issue 9, pp 911-923, 2010.

[6]Tosun G., "Statistical analysis of process parameters in drilling of AL/SICP metal matrix composite", The International Journal of Advanced Manufacturing Technology, Volume 55, pp477-485, 2011.

[7] Kabakli E., Bayramoðlu M., and Geren N., "Evaluation of The Surface Roughness and Geometric Accuracies in a Drilling process 
Using The Taguchi Analysis", Materials and technology 48 :1, 91-98, ISSN 1580-2949. 2014.

[8]Singh U.K., Dwivedi Manish , "Manufacturing process" , New Age International (P) Ltd., Publishers, Second Edition, 2009.

[9]Tamta N., Jadoun R. S., "Parametric Optimization of Drilling Machining Process for Surface Roughness on Aluminum Alloy 6082 Using Taguchi Method”, International Journal of Mechanical Engineering (SSRGIJME), Volume2, Issue7, 2015.
[10] Pradeep Kumar J., Packiaraj P. “ Effect of Drilling Parameters on Surface Roughness, Tool Wear, Material Removal Rate and Hoe Diameter Error in Drilling of OHNS", International Journal of Advanced Engineering Research and Studies(IJAERS), Volume I/ Issue III, 2012. 
|خلية عوال لملية التثقيب لسبائك الالمنيوم باعتماد طريقة تاكوجي

\author{
اسيل جميل هليل

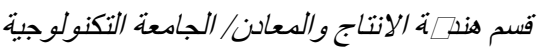 \\ البريد الالكتروني: yahoo.com
}

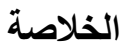

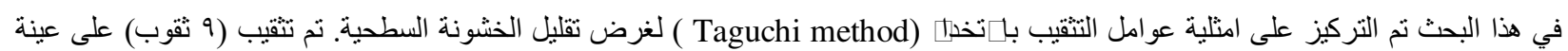

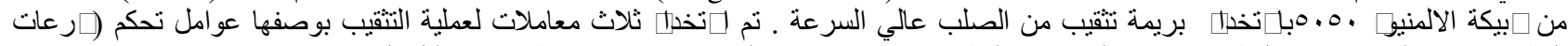

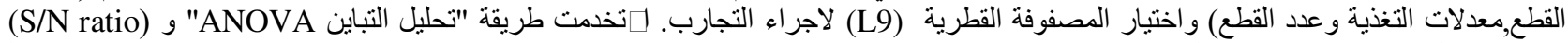

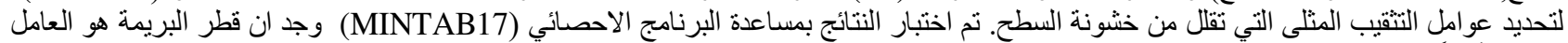

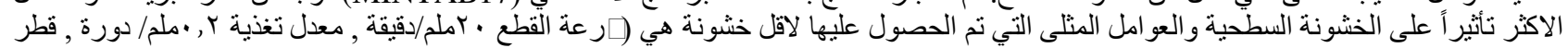

بريمة · (ملم). 